\title{
Common Sense, Science and the Specialization of Knowledge ${ }^{1}$
}

\section{Thomas Luckmann}

Universität Konstantz

\section{Introduction}

Common sense is a much maligned as well as highly praised form of knowledge. So is science. And the two seem in conflict because implicitly it is assumed or sometimes explictly claimed that either the one or the other is the only kind of sense there is. Unless one is to down them both, one should perhaps try to find out what particular kind of sense there is in the one and what in the other.

The task one sets oneself in trying to answer such a question is rather peculiar, however. Is one to claim an absolute standpoint from which to give passing grades to certain kinds of knowledge, failing marks to others? Or are we to resign ourselves to accept any claim to knowledge as being justified? I shall choose a middle road. In the main I shall try to describe rather than evaluate. But I am not without hope that an accurate description of their respective structures and a consideration of their functions will provide some criteria for the assessment of common sense and science, clarifying at the same time their relation to one another. I shall not pretend to have an unfailing Archimedian point in one of the transcendental critiques of knowledge. I shall not appeal to Kant at all and only indirectly to Husserl. Nor shall I rely on the common sense of the positivist tradition and take the superiority of scientific rationality for granted. Instead, I shall set myself a-justslightly more modest task. I shall first consider common sense and science in phenomenological perspective in order to see how they originate in human consciousness. Next I shall consider their functions from the point of view of the sociology of knowledge. First I shall sketch the universally human intentional activities which are presupposed in the constitution of experience as well as in the process of interpretation of experience and which, thus, lead to the acquisition of knowledge and its sedimentation in subjective stocks of knowledge. I shall then briefly consider the structure and the functional implications of the social distribution of knowledge and present two models of it which roughly summarize the empirical contexts of individual knowledge in society. As a result, the nature of common sense and of science as subjective and social facts should become somewhat clearer.

Another brief observation is in order, although it may be merely repeating the obvious. In a first approximation, we may consider common sense to be a structured and coherent set of orientations whose main function is to guide human action. Its empirical "location" is evidently the individual human being although it just as evidently needs not-in fact, empirically does not-originate exclusively in intentional activities of the individual. Much of common sense is socially derived. This process of derivation, however, also presupposes intentional activities on the part of the recipient, just as the social stock of knowledge itself is originally built up and consequently maintained in intentional activities. These points will require some elaboration later. 
For the moment it only needs to be noted that common sense is a universal fact of "normal" human existence. It is impossible to imagine ordinary members of our species living in their social worlds and in the natural environment of the species without some such conscious and more or less systematic way of steering their actions.

In contradistinction, science (even if we do not unduly restrict the term to modern science of the past three centuries) is a very specific, historically limited and, perhaps, unique way of systematizin sets of human orientations in reality. It may very well be that science is superior to common sense in more ways than one-although only one way, that of technological mastery, is really obvious. But the:e is no reason to consider science as a self-legitimating and self-legi:imated enterprise, unless we accept with Galileo that God has not only imposed a certain structure on the cosmos but also that only one kind of knowledge, providentially implanted in us by the same han $\mathrm{t}$, the knowledge "of squares, circles and triangles," is capable of deciphering that structure. An investigation of the origin and the functions of science as an individual and social human activity is likely to jrovide firmer ground for an assessment of common sense as well as science for believers and sceptics alike, especially if it can show how it came about that science and common sense are both similar in some ways and dissimilar in others.

Science is not the first, nor is it the only, systematization of the complex modes of human orientetion in reality. There are others which are equally unique historica!ly as, for examp!e, philosophy. Others again may be as universal as common sense: thus, for example, religion. One need not subscribe to any simple Comtean notion of an evolution of the human mind from religion to philosophy to science in lawful sequence to note that religion and philosophy were both of great importance in the filiation of science. All religions served to integrate into a meaningful whole variegated ways of human orientation in reality. Most, if not all, religions tended to dominate common sense, to impose their logic on it. Common sense under varying historical and social-structural conditions survived as best it could, in submission or subterranean opposition. In this regard science resembles religion. Science, too, is dominant as a systematizing mode of thought, as theory. It is a remarkable fact that religion hardly ever managed to supplant common sense as the guiding pragmatic principle of life-for ordinary people (I exclude the cognitive enclaves of religious virtuosi that dot the historical landscape). Is it likely that science will be more successful in this respect? Because of its technical superiority in solving many problems of everyday life? Or because it offers a superior cosmology-if it does that? (And again I exclude the cognitive enclaves of the technological savants idiots that dot the contemporary landscape.)

And now for another, and final, introductory remark. For reasons which will be given later, I do not consider it useful to define common sense merely by its distributional features; that is, as that form of knowledge which is generally distributed in society, any society, at a given time. I prefer to use the neutral term, general knowledge (as 
opposed to special knowledge) to refer to such distributional features. But common sense is, indeed, the hard core of general knowledge in all societies and in many, if not most, communities. Yet, it is only one part of general knowledge, that part which deals with everyday reality-and deals with it pragmatically. That is to say that the cognitive, affective, and moral dimensions of the way reality is viewed, segmented and reconstructed, experienced, interpreted and evaluated, are all determined by the pragmatic motive. Common sense is the human way to maintain life in the face of obstacles which cannot be wished away. It is the all-too-human and pedestrian way to cope. Evidently, everyday reality is not the only reality there is in human life. There are dreams, ecstasies, crises, and catastrophies of everyday life, and there are other modes of experiencing that which is extraordinary. Correspondingly, common sense is not the only kind of sense there is: There is always public or secret knowledge dealing with uncommon realities. Not all knowledge of extraordinary things is specialized: Some of it is common, although not common sense. The experience of ordinary and extraordinary realities is rooted in universal elements of human life and human consciousness, but the way such experience is interpreted and the precise location of the boundary between the ordinary and the extraordinary are constructed socially and are therefore historical rather than universal facts. Under certain, historically prevalent conditions, the construction of these facts tends to become an expert affair. In human history, there are more specialists of the extraordinary than the ordinary. Given the power that resides in the monopoly of the extraordinary, this is not especially surprising.

\section{On the Structure of Subjective Knowledge}

Subjective knowledge is built up from experience. This is so obvious that the statement needs to be specified if anything is to be gained from it. Subjective knowledge forms a structure of systematically interrelated elements which may be called a subjective stock of knowledge. The stock of knowledge is not the result of logical systemization on the part of the individual. In fact, individuals in the naive attitude of everyday life are not at all aware of the structure of their stock of knowledge. Their knowledge of what they know for practical purposes is in no manner analogous to the way in which a chemist is aware of the structure of his knowledge of chemistry, in addition to knowing chemistry. However, subjective knowledge functions in ways which reveal that structure to phenomenological description. The structure, it may be said in a summary of the findings of such description, is the result of the sedimentation of particular experiences in particular situations, of the subjective system of relevances operative at that time in the situation, in conjunction with whatever knowledge was already stored subjectively at that time. In addition, it is influenced by the subsequent "history" of that element of knowledge in an individual's life. We may roughly distinguish the following: simple sedimentation; recurrent use and routinization; re-use requiring modifications; abandonment and replacement by a new element. 
It hardly needs to be stressed that, strictly speaking, all experiences are sedimented. By experience I refer to those events in the stream of consciousness which stand out as topics to which the self attends and which are memorable rather than belonging to the flow of "petites perceptions" (as Leibniz called them). By definition, all experience therefore contributes to knowledge. Evidently, the amount of such contribution may be minute, or it may be highly significant. Significant contributions regularly originate in experiences in which a problematic situation had to be dealt with, or in which problematic aspects arose within an otherwise unproblematic situation. In both cases, the individual had to assess the situation with heightened attentiveness and draw upon past experience to some purpose. To use Dewey's phrase, he had "to stop and think", he had to interpret the situation. Such elements of knowledge thus consist of solutions to problems.

Subjective stocks of knowledge consist of three regions: of elementary and tacit knowledge, of routine knowledge, and of explicit knowledge; that is, knowledge in the narrowest sense of that term: Elementary tacit knowledge is that set of implications which accompany all experience and without which no experience is thinkable. Such knowledge is present in the horizon of the varied topics of experience and action; it is not normally made a topic itself. It consists of the (horizonal) awareness of the irreversibility of action and experience, of elementary orientation in space and time and of an awareness of the existence of others, including an awareness that such existence is in substantial aspects like mine. The last-mentioned kind of awareness is thematized somewhat more frequently than the others. This happens when it turns out that the tacit principle (which was called by Schutz the principle of the reciprocity of perspectives) must be modified in practical application.

Routine knowledge consists of basic skills which are acquired in a seemingly automatic way, for example, walking. It also consists of practical knowledge which requires a higher degree of awareness and conscious learning, such as speaking or driving a car. Finally, routine knowledge contains recipe-like knowledge, that is, acquaintance with various kinds of prescriptions, injunctions, and proscriptions with respect to particular kinds of action.

Evidently, skills, practical knowledge, and recipe-like knowledge do not form sharply separated kinds of routine; it is easy to imagine many transitions between them. Routine knowledge is particularly important for most practical purposes of everyday life. It enables us to cope in an economic fashion with recurrent and highly typical situations. After all, in everyday life a wide range of events, situations, and problems confront us again and again.

Explicit knowledge consists of separate items of knowledge, knowledge which was acquired step by step and which can be evokedwith more or less difficulty-in order to come to terms with particular situations. Normally, these items are linked to each other in a fairly systematic way. It must be stressed, however, that the principles which link them are not strictly analogous to those used in the sciences or other 
bodies of explicit theory. The structure of this area of knowledge can be best described along the following dimensions: first, familiarity, which is based on the adequacy of the typifications stored in the stock of knowledge to define adequately the components of a given situation; second, determinacy, which derives from the degree of explication which went into the original constitution of, and later amendments to, a given typification; third, clarity, which may be understood as a composite of determinacy and consistency with other items; and fourth, consistency, the amount of explicit contradiction which characterizes the relation between items in the stock of knowledge. It should be noted, however, that subjectively experienced inconsistencies are unusual. The amount of inconsistency which an "outside" analyst may find in a given subjective stock of knowledge is far greater than the amount of inconsistency of which an individual himself is normally aware. A fifth and final dimension is that of credibility, the degree of confirmation which a given item of knowledge has experienced: first, when it was originally sedimented in the stock of knowledge, and, second, when it was subsequently applied.

The arrangement of the items in a subjective stock of knowledge along these various dimensions is partly determined by its origins in a particular situation, especially by the situationally determined need for solving particular problems, and partly by the subsequent history of a particular item in recurrent, or frequent, or rare applications.

From a sociological point of view another consideration is more important. Subjective stocks of knowledge contain elements of general, common knowledge as well as elements of special, expert knowledge. Because these categories are derived from the structure of social stocks of knowledge and are, in a manner of speaking, imported into the organization of subjective stocks of knowledge, we shall consider this matter in a moment. First, I should like to draw attention to another, closely related, circumstance. For various analytic purposes it may be useful to distinguish between those elements that were constituted in autochthonous interpretive acts from those that are socially derived. A social stock of knowledge is, of course, originally built up in subjective activities. Everything begins, so to speak, with the subjective acquisition of items of knowledge; the next step is the objectivation of subjective knowledge in communicative acts and their results, i.e. texts; and, finally, we reach the point in which objectivated knowledge is transmitted and internalized again. Subjective stocks of knowledge have, therefore, logical priority. Empirically it is the case, however, that an historical social stock of knowledge always precedes the building up of any given subjective stock of knowledge.

\section{On the Structure of Social Stocks of Knowledge}

A social stock of knowledge is built up in subjective activities. I have already indicated that the first step is an objectivation of subjective processes. This may take several forms. It may be that the original process in which knowledge was subjectively acquired is observable and observed. The subjective solution to a problem is thus transmitted only 
if the process of solving the problem is observed directly. Another possibility consists in making use of the results of the process of acquisition without being present at the process which led to the solution of the problem. Such solutions may be objectivated in the form of artifacts, tools, or may consist of mere traces in the world, such as a footpath. In other words, the solution of the problem may be "imprinted" on nature in some fashion. Finally, solutions to problems may be transmitted on purpose by means of various sign systems, among which language is evidently the most important.

It hardly needs to be said that not every bit of subjective knowledge is objectivated. Nor is every item of objectivated knowledge a candidate for the social stock of knowledge. Another presupposition for the admission of subjective elements of knowledge into the social stock of knowledge is, in addition to objectivation, the general or, at any rate, a more than individual relevance of the solution to a problem.

The sedimentation of subjective elements of knowledge in a social stock is not analogous to the subjective sedimentation of knowledge, although it presupposes such processes. In addition to objectivation and social relevance, it is also based on the historical cumulation of knowledge in social institutions. Knowledge, thus, becomes independent from the finitude of individual life. Elements of knowledge (solutions to problems, rules regulating the application of knowledge, etc.) are transmitted by way of special procedures and "stored" in particular institutions. In preliterate as well as literate societies such procedures and institutions range from the family, schools, and apprenticeships to more obvious storage facilities such as libraries, museums, and so forth. In the process of storage, a certain degree of systemization is normal; it consists, at the very least, of a taxonomic ordering of items.

One of the most important tasks of the sociology of knowledge is to analyze the relation of systems of knowledge to their social structural basis. A first step in this direction is conceptual: elementary models of the distribution of knowledge serve to draw attention to empirical similarities and dissimilarities in the way in which knowledge is organized and transmitted in different societies.

\section{Simple Social Distribution of Knowledge}

It is hardly possible to imagine something like an homogeneous distribution of knowledge. If one person is to know exactly the same as another person, the range of items in the social stock of knowledge should have to be identical with the range of items in each of the subjective stocks of knowledge. What circumstances would allow for such a state of affairs? First, all subjectively acquired knowledge would have to be generally relevant, and that could be imagined only if all problems faced by one person were also problems faced by all other persons. In other words, everybody would have to have the same interests and confront the same situations. Second, one should have to neglect the temporal and spatial conditions of communication. The cleavage between the objectivation of knowledge and the interpretation of an objectivation, the difference between encoding and decoding, would 
have to be eliminated. Finally, we should have to ignore the historical accumulation, and correspondingly, the dissipation, of knowledge. That is to say that as soon as a given range of knowledge had been established as adequate for coping with standard problems in standard situations, all further acquisition of knowledge, including the modification of already existent elements, would have to be stopped. The construction of a generally homogeneous distribution of knowledge thus evidently rests on untenable premises. 'The moment one person acquires a particular element of knowledge and transmits it to another, that element is not quite the same for the two persons: it was acquired independently by one individual and is socially derived for the other.

We may, however, begin to relax these presuppositions to such an extent that they become more realistic and then formulate a model of a simple, although not truly homogeneous, distribution of knowledge. It cannot be denied that certain differences in human nature precedephylo- and ontogenetically-their cultural over- and underdetermination. There is a certain degree of sexual dimorphism, there are other variations in body structure and behavioural capacity, and there are the obvious facts of maturation and aging. Such genetically determined differences are not simply mirrored in social relevance systems. Although social relevance systems in their full historical variety do originate in nature as much as they then transform nature in culture. At least the simplest, historically and culturally articulated differences in the kinds of problems faced by human beings and the way in which solutions to such problems are defined socially, rest on "natural" differences.

Now to turn to another of the original premises to be relaxed: biographical differences in the subjective course of experience lead to a kind of individual perspectivism. Even relevance systems that are highly socialized undergo a certain degree of individual variation by virtue of their location in a unique biographical context. As a result of this variation, knowledge, which is interpreted experience, is sedimented in a subjective stock of knowledge in biographically typical ways, and these ways are often socialized themselves. Typical courses of human life are thus socially constructed as models upon which the social transmission of knowledge is based. Age groups, for example, are often defined socially as educational generations.

And now we turn to the final presupposition to be relaxed: although it is inconceivable that in any human society the acquisition and accumulation of knowledge should be completed once and for all, at a specifiable point of saturation, there are evidently kinds of societies in which knowledge is modified only slowly and in which new elements of knowledge are added only under exceptional circumstances. In such societies specialization of knowledge will not proceed very far; systemization and the elaboration of "theory" will be minimal. In consequence, in societies characterized by simple distributions of knowledge, everything that is stored in the social stock of knowledge is accessible to everyone. More precisely there is nothing in the structure 
of knowledge which would oppose the acquisition of knowledge by anyone. In fact, there usually are institutional barriers to the acquisition of some knowledge, barriers which have to do with the distribution of power in society but not with the structure of knowledge as such. Knowledge may be made sacred and/or secret, and social institutions may emerge to restrict knowledge to certain groups or socially defined social roles.

Thus, not all problems are imposed on all members of society, not all problems are imposed on them in the same way, and even those which are imposed on everyone are not imposed on them at the same time. In our model we assume that the differentiation of the social relevance structures leads to the following organization of the way in which knowledge is routinely transmitted: The socially defined types of persons for whom different solutions are considered relevant are at least indirectly based on biogenetic differences and on stages of maturation. A social stock of knowledge that does not have at least this minimal differentiation in the distribution of its elements cannot be easily imagined.

When we think of common knowledge, and even more so when we refer to specialized knowledge, our main attention is directed to systems and sub-systems of explicit knowledge. For many social and individual purposes such systems are particularly important. It should be noted, however, that both common and special knowledge contain, in addition to explicit knowledge, elementary skills, practical knowledge, and recipelike knowledge of most diverse conformations. There are elements which are components of "normal" common knowledge in all societies, for example walking; typical orientations in space and time, and highly general and "tacit" rules of behavior that govern the maintenance of distance to others, such as greetings. Together with language, explicit and "tacit" components of common knowledge form a common sensical system or orientation in reality. Beyond such general statements there is little that can be said about the "contents" of the various categories and domains of knowledge. What is common knowledge in the form of general recipes in one society may be highly explicit and fairly systematic special knowledge in another.

Common knowledge may be formally defined as knowledge which is routinely transmitted to everyone, special knowledge as knowledge which is routinely transmitted to clearly specified social types. Even in societies characterized by a simple distribution of knowledge there is some specialization of knowledge. Access to such knowledge is institutionally controlled; without such control everyone could acquire whatever little special knowledge there is. A qualification must be added; there seem to be certain kinds of extraordinary knowledge that require special aptitudes, as for example in trance-shamanism. Doubtlessly, not everyone has a plausible motive to acquire special knowledge, and institutional barriers prevent general acquisition of such knowledge anyway. It is important to note, however, that in this type of society everyone krows who possesses special knowledge. In other words, the social distribution of special knowledge is, in such societies, an 
element of common knowledge. One of the consequences is that available knowledge about reality in general and about the social world in particular is rather faithfully represented in the subjective stocks of knowledge of its members.

\section{Complex Social Distribution of Knowledge}

Evenness or unevenness in the distribution of knowledge is one of the obvious criteria according to which common knowledge is distinguished from special knowledge. It may seem a bit of a paradox, therefore, if I now suggest that the model of a complex distribution of knowledge is characterized by a certain unevenness in the distribution of common knowledge. Is this not a contradiction in terms?

As was shown, common knowledge consists of social objectivations of solutions to such problems as are relevant for "everyone." Who is hiding behind this "everyone?" It was stressed earlier that problems that have to be met by everyone do not appear in identical perspectives to everyone; they are filtered, as it were, through the interpretive and experiential contexts of a unique biography. The typical, socially objectivated solutions of problems are, therefore, subject to modifications by such contexts. In addition, the transmission of knowledge from one person to another occurs in concrete social relations and concrete communicative processes. These are immersed for "everyone" in the meaning context of their biographical uniqueness. As long as the modifications in knowledge which result from such biographical contextualization remain idiosyncratic, they are of no consequence for the structure of the social stock of knowledge. In societies characterized by simple distributions of knowledge, uniqueness of biography is a negligible factor. The modifications of social elements of knowledge occur in the process of internalization and remain confined to subjective stocks of knowledge. Common knowledge in this type of society is equally distributed; the inevitable inequalities in the distribution even of common knowledge are not bound to social roles and are neither institutionalized nor determined by anything like class position. With respect to the social structure and to the social distribution of knowledge, these inequalities are, in fact, contingent.

It is fairly obvious, however, that "everyone's" problems can be confronted by everyone in similar biographical contexts and dealt with in similar subjective relevance systems only in societies characterized by a very simple social division of labor. As soon as the division of labor is more highly developed and as soon as social strata (castes, classes) are formed around political, economic, and other (e.g. religious) factors, the situation begins to change. The perspectives in which the same problems are viewed are no longer the same for all members of society, nor do they merely vary in purely idiosyncratic ways. The division of labor produces structurally variable as well as structurally similar biographies; class position results in similar interests and attitudes. These structural biographical similarities are categorized in more or less obligatory ways, by insiders and outsiders, from within and from without. This is particularly obvious in caste-based and feudal societies; but it 
also applies to social classes in modern industrial societies. The social transmission of elements of common knowledge is modified at least in part by class "codes." It should be noted that these remarks refer to common knowledge. Common knowledge now becomes differentiated into separate versions, yet they remain versions of common knowledge. They continue to serve as solutions to common problems. The solutions are still generally distributed-but in versions determined by the peculiarities of a historical social structure. It is in this sense that one may speak, somewhat paradoxically, of a certain unevenness in the social distribution of common knowledge.

Another important trait of such societies- and it is a particularly important one for our present considerations-is an increase in the specialization and in the theoretical elaboration of special knowledge. There are more areas of life which are dealt with by experts of one kind or another. In comparison with societies characterized by a simple social distribution of knowledge, this may appear at first as a merely quantitative difference. As socially relevant knowledge is more highly specialized, however, and as it acquires a distinctly theoretical structure, it tends to become less "practical," less "commonsensical," and, at the same time, it gains in autonomy. Such autonomy is, of course, always restricted. Nonetheless, many domains of special knowledge are further and further removed from common knowledge and develop internal "logics" and "methodologies" of their own. The distance between laymen and experts grows. Relatively complex and fairly long sequences of training, apprenticeship, schooling, and the like are necessary for the acquisition of special knowledge. Furthermore, the transmission of specialized knowledge itself tends to become specialized. In other words, not only do the various domains of special knowledge form systems of ideas, the social transmission of such knowledge also becomes institutionally "specialized." The acquisition of special knowledge is defined according to a pattern of socially defined steps, such as careers. Quite apart from institutional restrictions-which tend to be ideologically minimized in modern, more or less egalitarian societiesnobody could possibly acquire all the specialized knowledge available in the social stock of knowledge of complex societies.

The finitude of individual life alone- disregarding entirely the intraspecific variation of abilities and the intra-societal inequalities of access to the acquisition of highly specialized knowledge - prevents any one individual from acquiring more than a limited segment of the social stock of knowledge. In societies of this type, specialized knowledge in its entirety ceases to be accessible to everyone. As we have seen, subjective stocks of knowledge and social stocks of knowledge are partly mirrored in all subjective stocks of knowledge. In societies characterized by a complex distribution of knowledge, however, this is no longer the case.

Another trait of this type of society is that the facts of the social distribution of special knowledge are no longer an element of common knowledge. Everyone knows, of course, that he is not in possession of all the knowledge that is available in a given society. Everyone knows that there are all kinds of experts. But the precise distribution of specialized 
knowledge is no longer part of common knowledge. It becomes part of specialized knowledge. One of the consequences is that the social stock of knowledge in its entirety becomes opaque for everyone. The degree of the remaining transparency, however, is itself socially distributed. This incidentally is an important characteristic of the age in which science is the dominant mode of specialized knowledge. The specialization of knowledge into relatively autonomous domains and the differentiation of the institutional basis of knowledge trigger a process of increasing theoretical systematization. The connection between the specialized systems of knowledge and the totality of everyday life weakens significantly. "Higher" forms of knowledge develop in consequence of structural and intellectual specialization. Once a high degree of autonomy is reached-and, it hardly needs to be pointed out, this occurs only under rather unusual sociohistorical conditions-systems of knowledge are transmuted into purely ideal systems. That does not mean, of course, that the "higher," quasi-autonomous forms of knowledge, such as the sciences, are no longer socially determined, socially objectivated and socially transmitted. But an impersonal system of communication that frees the transmission of knowledge to a significant extent from face-to-face contacts, as is the case in literate societies and, even more dramatically, in societies with electronic mass media, makes such knowledge accessible for "everyone" again. Everyone is given an imaginary ticket to a musee imaginare of ideas.

\section{On the Historical Change of Social Distributions of Knowledge}

It has been already noted that the proportion of common knowledge to special knowledge is changeable. In societies characterized by simple social distributions of knowledge, common knowledge accounts for most of the knowledge there is, whereas special knowledge, important though it may be, amounts to little. As specialized knowledge in such societies typically pertains to extraordinary levels of reality, we may say that common sense is (almost) all the sense there is. With the increasing division of labor and most certainly with the emergence of modern capitalism, with the rise of science and spreading industrialization, the proportion of common knowledge to special knowledge shrinks. This structural transformation of the social stock of knowledge is not to be confused with simple changes in the content of what is common knowledge and what is special knowledge. A plant taxonomy, for example, may be common knowledge in a tribal society while reading and writing are special knowledge; in modern industrial societies the situation is reversed.

What is simple common knowledge in one generation and is transmitted to all members of that generation may sooner or later change into versions of common knowledge which are transmitted routinely only within particular social strata. Later again, such versions of common knowledge may be systematized and turned to special knowledge whose transmission is institutionally restricted. At the same time, it is easy to imagine a reverse development. New problems may arise which are potentially problems for everyone. But they need not yet be seen as problems by everyone because of the traditional persistence of attitudes 
with which reality is viewed. Such problems may be, however, discovered as problems by prophetically minded experts. Solutions that are in fact (although not seen to be) generally relevant may then be found in advance of a general awareness of the problem. The solutions thus remain, for the time being, elements of highly specialized knowledge.

The obvious question which sociologists of knowledge must ask is under what concrete empirical conditions such specialized knowledge turns into common knowledge. Certain institutions, in particular the social organization of specialized knowledge, and certain types of attitudes embedded in a historically given view of the world may either aid or hinder this process. In a period in which new problems arise rather frequently and perhaps fatefully, and in which the specialization of knowledge, especially of scientific knowledge, has reached amazing proportions, this question is of obvious practical importance. Notwithstanding the increasing interest in this matter in recent years, there is still much to learn about the limits set to the possibility and perhaps even desirability of infusing science, distinctly a form of specialized knowledge, into common sense.

\section{Science as Specialized Knowledge}

In the light of its historical origins and considering its location in the social stock of knowledge, science is a form of special knowledge. It shares some, but not all the characteristics of most other kinds of special knowledge: It is neither a specialized work-discipline, nor a mere technology, nor is it a specialized approach to salvation or a theoretical version of a generally plausible cosmology. However, this assertion needs some qualification. After what may be perhaps rather misleadingly called the secularization of the world view in Western Culture, science did usurp a central social function. From a different point of view one could also say that a central social function was thrust upon science by that peculiar ideological development to which we generally attach the term Enlightenment. Traditionally, religion had been the particular form of special knowledge which claimed total jurisdiction and superior status. Religiously defined models formed a cognitive, affective, and moral ideal to be approximated. At the very least, they provided an elevated rhetoric to camouflage ordinary common sense. By careful strategies, various universal religions had reached a dominant position in society although not without considered compromises with that part of common knowledge which was concerned with everyday realities. Now that religion has lost this position, the sciences increasingly seem to have inherited traditional religious functions and obtained an analogous position of dominance vis-a-vis common sense. The cosmological failure of physicalism and biologism (among the more likely pretenders to this religious inheritance) as well as psychologism and sociologism (among the less likely ones) show that science, in its separate branches and added together, cannot successfully maintain its claim to this inheritance. Whatever else it can do better than religion, there are some things it cannot do at all. 
Certain problems also emerge on the conceptual level. Thrusting aside the growing suspicion that a reflection on the metaphysical, ontological, and epistemological premises of modern science is not really the futile search for evanescent certainties which it was generally considered to be by the open or well-camouflaged adherents of common sense in science, it may be more useful to consider a closely related, but more easily answerable question. If science is special knowledge with quasi-religious claims to dominance over common sense, what are the different functions of common sense and science.

Common sense is general knowledge pertaining to everyday realities. It is the central part of the social stock of knowledge and serves to provide a total orientation for the individual. It must cope with all kinds of "normal" situations in his life. At the same time, that orientation is existential in the hardest pragmatic sense that can be given to that term. It must be specific: that is, useful in one concrete case after another. It must deal with all kinds of situations in his life. From an outside point of view we may say that such knowledge must be effective in the management of such problems as are commonly imposed upon an ordinary course of life-of the ordinary members of a society-by nature and by various social institutions. It need, however, function only in everyday situations, for ordinary conduct that is located in a concrete, historical social structure. This means, among other things, that such knowledge need not reconstruct cognitively a unitary reality in logically consistent ways and need not formulate it on highly abstract levels. The point of particular importance is that common sense must be subjectively adequate. This means that it must be of a kind which takes into account the finitude of subjective existence. It must be adjusted to the average limitations of experience and intelligence in an ordinary individual's life. Special knowledge, and this is even more obviously true for science than, for example, religion, can afford to neglect subjective finitude as well as individual limitations because of its historically cumulative character and its ability to reconstruct reality in abstract, rational formulae.

In comparison with the traditional functions of religion, science is, however, limited in a different way. Science, by its empiricist principles of verification) or corroboration) is knowledge that pertains exclusively to a reality whose manifestations are perceptually accessible to everyone in the ordinary world of everyday life, no matter how complex the technology of observation, how far removed its concepts from the level of ordinary experience, or how incomprehensible its formulae are to common sense. The "home base" of modern science is also the "home base" of common sense. Science as well as common sense rest upon a form of realism that is philosophically naive. It may not stand up to a transcendental critique of knowledge, but it passes the pragmatic test of ordinary experience. Philosophically naive realism may be intellectually inadequate in final analysis, but it succeeds by its own effectively narrow criteria. 


\section{Rationalization or Common Sense?}

Under the conditions of modern life and in the light of the development of Western culture, rationalization seems to mean scientific rationalization. On closer examination this meaning may include various things: imposition of scientific modes of thought upon common sense, routinization of the use of technological results in everyday life, or infusion of items of scientific discourse into ordinary language leading to a kind of scientific Franglais.

It is a trivial contemporary observation that applications of science permeate common sense in all spheres of everyday life. Various results of technological knowledge have indeed become part of routine and practical knowledge of all members of modern industrial societies. But, in spite of all that, the structure of subjective stocks of knowledge and the essential characteristics of common sense are not necessarily more scientific than before the Industrial Revolution. Because we are capable of turning on light-switches, using a camera, or driving a car, we are not more rational in the conduct of our lives than we were in horse-andbuggy times or, for that matter, before the "invention" of the wheel.

Furthermore, the vocabulary of the language of science has gained common currency in ordinary language. Ordinary language, however, is both more flexible and, with respect to certain key semantic areas, more vague than the various languages of science. The insertion of originally scientific terms in ordinary language, such as genes, correlation, social role, repression, makes little difference to the complex mixture of the referential, indicative, and phatic functions of language in the speech acts of everyday life.

The common sense of modern industrial societies, however, may have become "rationalized" in a less superficial way. Partial : models explaining the relation of antecedents and consequences, the interrelation of elements in certain regions and on certain levels of reality have been shifted en bloc from various sciences into common sense. Needless to say, they undergo significant transformations by being inserted into the pragmatically oriented structure of common sense. Yet they may serve as rather general schemes of orientation. Darwinism did change, perhaps definitively, our way of looking at nature; knowledge about bacilli, bacteria and such items did change certain everyday habits as well as more general modes of thought about health and sickness.

A wholesale transfer of scientific cosmologies to common sense, however, seems more than unlikely. The historical failure of scientism as a general philosophy of life was not accidental. No matter how one adds up all the sciences or reduces them to one, they are entirely incapable of substituting their cognitive schemata for the kind of knowledge required to regulate action in ordinary situations: the kind of knowledge which permits routinization of recurrent performances, the kind of knowledge which is not limited to the ordinary reality of everyday life but allows for an "outside," transcendental infusion of meaning into ordinary life which, after all, is subject to mortal crises. 
To add a final remark on the social sciences, we are in a cleft stick and wriggling. It is obvious that we cannot give up the common cosmological goal of all science: understanding the world which implies cognitive distance and existential detachment from what we are studying. But what we are studying is ourselves, and we, the people, are not existentially detached. The solution may be to keep on wriggling in what a euphemist would call "creative tension," but what I think is more aptly described as tightly controlled schizophrenia. We are subjects and objects, and if we want to practice general understanding rather than romantic intutition, we have no option but to alternate from the naive attitude of everyday life to the theoretical attitude of science and back.

\section{Notes}

1. This article was presented at the Phenomenology of Childhood Conference, University of Michigan, April, 1982. It is based on a paper scheduled for publication in F. U. Hoolthoon, D. A. Olson, Common Sense: A Focus on the Transparent-Proceedings of the Netherlands Institute for Advanced Study in the Humanities and Social Sciences, Wassenaar (in press). A shorter version of this paper appeared in German (Peter Janich, ed., Wissenschaftstheorie und Wissensforschung, Munchen 1981). The detailed phenomenology of the subjective constitution of knowledge upon which I draw in this essay may be found in Alfred Schutz and Thomas Luckmann, The Structures of the LifeWorld, Evanston: Northwestern University Press, 1973. A sociological analysis of the functions of the social distribution of knowledge is to be found in Peter Berger and Thomas Luckmann, The Social Construction of Reality, Garden City, New York: Doubleday and Company, 1966. 